\title{
ESTETIKA NUSANTARA DALAM KARAKTER GIM LOKAPALA
}

\author{
Lingga Agung ${ }^{*}$, Tata Kartasudjana ${ }^{2 *}$, Anggit Widya Permana ${ }^{3 *}$ \\ Desain Komunikasi Visual Fakultas Industri Kreatif \\ Universitas Telkom \\ Jl. Telekomunikasi, No. 1, Terusan Buahbatu-Bojongsoang, Kec. Dayeuhkolot, Kota Bandung, \\ Kode Pos 40257 \\ Jawa Barat. Indonesia \\ Email: linggaagung@telkomuniversity.ac.id,tatakartasudjana@gmail.com,awpdesign@yahoo.com
}

\begin{abstract}
Abstrak
Lokapala adalah gim Multiplayer Online Battle Arena (MOBA) karya studio anak bangsa, Antarupa. Semua karakter (Ksatriya) di dalam gim ini diangkat dari tokoh sejarah, mitologi, dan legenda Nusantara. Oleh karenanya, dalam konteks estetika para Ksatriya merepresentasikan kebudayaan Nusantara itu sendiri. Namun seperti apa dan bagaimana representasinya adalah persoalan yang mesti ditelaah. Oleh karena itulah penelitian ini dilakukan. Penilitian ini adalah kualitatif, dari gim Lokapala ini kami mengambil data-data visual masing-masing karakter, mengklasifikansikannya, dan mendeskripsikannya. Untuk menelaah estetika para Ksatriya, kami menggunakan teori estetika Feldman. Teori ini digunakan karena relevansinya yakni estetika sebagai representasi kebudayaan. Adapun hasil dari penelitian ini, estetika Nusantara hanya terlihat melalui karakternya dalam simbolsimbol 'budaya Nusantara' yang sudah umum, seperti dalam busana dan elemen estetis lainnya-tidak mendalam, apalagi filosofis. Ketidak mendalam ini merupakan sesuatu yang niscaya karena dalam desain karakter gim ada beberapa hal yang perlu diperhatikan seperti kebutuhan industry dan masalah teknis lainnya.
\end{abstract}

Kata Kunci: $M O B A$, lokapala, representasi, estetika nusantara.

\begin{abstract}
Lokapala is a Multiplayer Online Battle Arena (MOBA) created by the Indonesia game studio, Antarupa. All characters (Ksatriya) in this game are based on historical figures, mythology, and legends of the archipelago. Therefore, in the aesthetic context, the Ksatriya represent the culture of the Indonesia itself. However, what it looks like and how it is represented is a matter that must be studied. Therefore, this research was conducted. This research is qualitative research, from this Lokapala game we take the visual data of each character, classify it, and describe it. To examine the aesthetics of the Knights, we use Feldman's theory of aesthetics. This theory is used because of its relevance, namely aesthetics as a cultural representation. As for the results of this study, the aesthetics of the Indonesia is only seen through its characters in the symbols of 'Nusantara culture' which are already common, such as in clothing and other aesthetic elements-not deep nor philosophical. This lack of depth is something that is necessary because in game character design there are several things that need to be considered, such as industry needs and other technical issues.
\end{abstract}

Keywords: MOBA, lokapala, representation, nusantara aesthetic.

\section{PENDAHULUAN}

Gim Mobile Legend: Bang Bang (MLBB) merupakan salah satu gim Multiplayer Online Battle Arena (MOBA) yang paling popular di Asia Tenggara, termasuk di Indonesia. Bahkan pada tahun 2020, Indonesia berada di peringkat 5 pengguna MLBB terbanyak di ASEAN.

Hal yang menarik dari MLBB adalah karakterkarakternya-yang disebut hero-yang banyak mengadaptasi tokoh sejarah, mitologi, dan legenda dari berbagai negara, seperti Minotaur dari Yunani, Alucard (Dracula) dari Romania, Guinevere dan Lancelot dari Inggris, Zilong dari Cina, Lapu-lapu dari Filipina, Gatotkaca dan Kadita dari Indonesia.

Popularitas MOBA dan MLBB membuat developer gim di Indonesia tidak ingin ketinggalan. Adalah Antarupa Studio yang pada tahun 2020 lalu merilis gim MOBA Lokapala. Gim ini sangat menarik karena karakter-karakter di dalam gimnya mengadaptasi 
tokoh-tokoh sejarah, mitologi, dan legenda Nusantara-disebut Ksatriya.

Jinno, misalnya, mengadaptasi Gajah Mada dan Illya mengadaptasi Gatot Kaca. Adaptasi tokoh-tokoh sejarah, mitologi, dan legenda Nusantara ini dapat dilihat sebagai sebuah upaya dalam pelestarian budaya Nusantara di dalam medium gim.

Gim pada dasarnya merupakan sebentuk kebudayaan yang sangat bertumpu pada visualitasnya. Begitu juga MOBA karena merupakan bentuk terkini dari gim. Oleh karena itu, MOBA dapat dikategorikan ke dalam fenomena budaya karena telah menciptakan kultur baru seperti 'Mabar' (Main Bareng) dan lain sebagainya. Selain itu, MOBA dapat menjadi media untuk menjaga, melestarikan, dan memperkenalkan kembali warisan budaya kita.

Salah satu cara untuk melakukan hal tersebut di atas adalah dengan memberikan visualitas yang mengadaptasi warisan budaya kita, seperti halnya yang dilakukan oleh Antarupa Studio dalam gim Lokapala ini. Karena visulitas inilah, Lokapala sebagai gim MOBA memiliki dimensi estetikanya tersendiri.

Estetika pada dasarnya adalah ilmu tentang keindahan dan keindahan selalu dihasilkan dari kontruksi manusia yang kemudian menjadi bagian terpenting dari kehidupan manusia. Keindahan yang dimaksud di sini tidak melulu keindahan dalam pengertian tradisionalnya melainkan keindahaan yang menjadi representasi dari sebuah budaya tertentu.

Visualisasi karakter-karakter Ksatriya dalam gim Lokapala secara estetika merepresentasikan kebudayaan Nusantara itu sendiri-setidaknya sebagai sebuah upaya ke arah tersebut. Sebagai sebentuk representasi, karakter-karakter Ksatriya ini menyimpan nilai-nilai dari apa yang direpresentasikannya.

Dalam penelitian ini, pertanyaan kami yang paling mendasar adalah, apakah karakter-karakter Ksatriya dalam gim Lokapala ini sungguh-sungguh merepresentasikan budaya Nusantara secara solid dalam visualitasnya di atas? Atau jangan-jangan hanya mengikuti tren saja. Oleh sebab itulah, penelitian ini menjadi penting karena daripadanya kita dapat melihat bagaimana budaya Nusantara secara estetika direpresentasikan dalam bentuk terkini melalui media terkini.

\section{KAJIAN TEORI}

\section{Definisi Estetika}

Estetika pada dasarnya adalah ilmu yang berusaha untuk memahami keindahan-khususnya di dalam seni. Biasa disebut sebagai pengetahuan tentang hal-ikhwal keindahaan. Ada pula yang mendefinisikannya sebagai filsafat keindahan atau filsafat seni. Secara etimologis, estetika berasal dari kata sifat dalam bahasa Yunani, aisthetikos, yang artinya 'berkenaan dengan persepsi'. Bentuk kata bendanya adalah aesthesis, yang artinya 'persepsi inderawi'. Sementara bentuk kata kerja orang pertamanya adalah aisthanomai, yakni 'saya mempersepsi' (Suryajaya, 2016: 1). Jadi secara sederhana estetika adalah ilmu tentang keindahan dalam seni.

\section{Karakter Dalam Gim}

Karakter-karakter di dalam gim adalah sebuah teks yang dikontruksi sedemikian rupa sehingga ia dapat menjadi subjek yang 'mandiri', terlepas dari nilai-nilai yang melekat pada karakternya tersebut. Ketika karakter dalam gim ini menjadi 'mandiri' maka desain karaktrer tersebut secara leluasa dapat menjelaskan backstory dan personality yang kemudian mampu 'mengikat' penggunanya dalam konteks yang terkini-s Engagement.

Menurut Senoprabowo, dkk. karakter merupakan representasi dari pemain yang memainkan game. Karakter membuat pemain menjadi fanatik. Pemain cenderung memainkan karakter yang menjadi pilihannya sejak awal, yang dianggap mewakili identitas atau jati dirinya (2017: 163).

Sedangkan menurut Smith (1995: 82-83), ada 3 aspek dari Character Engagement: (1) Recognition, relating to the physical character, (2) Alignment, related to socio-cultural, (3) Allegiance is how character in the character's physical beauty, expressions, and morals.

\section{METODE PENELITIAN}

\section{Metode Penelitian Kualitatif}

Penelitian ini adalah penelitian kualitatif, menurut Howard Lune dan Bruce L. Berg penelitian kualitatif berurusan dengan makna, konsep, definisi, karakteristik, metafora, simbol, dan deskripsi sesuatu (2017: 12).

Dalam rangka mencari kesemua hal di atas, di dalam peneltian ini kami mengambil data langsung dari gim Lokapala. Kami mengkhalifikasikan karakter-karakter Ksatriya berdasrkan rolenya, kemudian mendeskripsikannya, dan kemudian memilih karakter yang memiliki relevansi dengan penelitian ini. Karakter-karakter Ksatriya dalam penelitian kualitatif sendiri dapat lihat sebagai sebuah sebuah teks. 
Oleh sebab itu, karakter-karakter Ksatriya ini dapat dianalisis dengan mengidentifikasikan unsur-unsurnya yang tidak lain merupakan bagian dari fenomena kebudayaan itu sendiri. Di dalam gim Lokapala ada sekitar 20 karakter Ksatriya. Namun yang akan kami analisis dalam penelitian ini hanya 4 karakter sajadipilih karena relevansinya yakni signifikansi estetis dalam latar belakangnya yang solid sebagai bagian dari budaya 'Nusantara'. yaitu: Jinno, Vijaya, Nala, Ilya. Ke-empat karakter yang kami pilih ini didasarkan atas signifikansinya dengan relasi kebudayaan Nusantara.

\section{Teori Estetika Edmund Burke Feldman}

Untuk menganalisis ke-empat karakter di atas, kami menggunakan teori Estetika dari Edmund Burke Feldman. Ada empat tahap analisis yang mesti dilakukan, yakni: (1). Analisis Deskripsi: Mengidentifikasi suatu karya sehingga informasi yang didapat akan menjadi petunjuk tentang arti dan maksud dari karya tersebut. (2). Analisis Formal: Melihat hubungan antar unsur visual yang ditampilkan, sertai mengurai hasil antar hubungan tersebut, (3). Interpretasi: Menerangkan pemikiran tentang apa yang dimaksud atau apa yang berada di balik suatu karya visual, dan (4). Penilaian: Merupakan sintesa dari analisis antar unsur yang terjadi dalam karya seni yang dianalisis (Soewardikoen, 2019: 91-92).

\section{HASIL DAN PEMBAHASAN}

\section{Hasil}

Ke-empat karakter di dalam gim Lokapala yang di analisis telah menerapkan prinsip-prinsip Character Engagement, seperti: (1) Recognition, relating to the physical character, dengan adanya simbol-simbol tertentu yang merujuk kepada tokoh yang didasarkannya (2) Alignment, related to socio-cultural, terkait dengan latar belakang sosial-budayanya walaupun Nala memang yang sangat jauh, (3) Allegiance is how character in the character's physical beauty, expressions, and morals di mana keempat karakter ini memang didesain untuk lebih 'akrab' bagi generasi yang lebih muda.

Namun, sayangnya, usaha untuk 'lebih akrab' ini menyebabkan visualitas karakternya secara estetis hanya menggunakan simbol-simbol kultural dari warisan budaya Nusantara yang sebetulnya sudah sangat umum. Seperti di dalam penamaan, latar belakang karakternya, sampai busana, dan elemen estetis yang digunakannya. Apalagi nilai-nilai filosofisnya yang sama sekali tidak 'tervisualisasikan'. Namun, dalam konteks desain karakter, hal ini menjadi niscaya karena terkait dengan permasalahan teknis dan komersial.

\section{Pembahasan}

Saking kompleksnya kebudayaan yang kita miliki, kadang-kadang upaya untuk mendefinisikan budaya Nusantara seringkali merupakan sesuatu yang sangat sulit untuk dilakukan. Namun Pisani, dengan cerdasnya menyebut kebudayaan kita sebagai, "A nation whose multicolored fragments seem to settle into different patterns with every shake of history and circumstance" (2015: 7).

Oleh karena itu, definisi estetika Nusantara pun menjadi sama kompleksnya. Sehingga definisi yang muncul merupakan definisi yang lebih kontekstual dengan kompleksitas yang ada dan melalui bentukbentuk visual kita lebih mudah untuk mengidentifikasikannya. Karena ketika orang akan membicarakan estetika Nusantara sebagai suatu konsep yang utuh atau komprehensif, maka konsepkonsep itu harus dibangun dan/atau bersumber dari kenyataan-kenyataan empirik dari sekian banyak kesenian yang dihasilkan oleh komunitas etnis atau suku bangsa Nusantara ini (Triyanto, 2008: 2).

Dalam penelitian ini, estetika Nusantara kemudian berelasi dengan bagaimana nilai-nilai kebudayaan Nusantara berkelidan dengan konteks terkini. Yang di dalam penelitian ini berada di dalam media gim MOBA Lokapala.

Estetika Nusantara kemudian dapat kita pahami sebagai nilai-nilai keindahan yang umumnya merupakan bentuk ekspresi budaya dan acapkali menandai posisi strategisnya melalui bentuk-bentuk yang simbolikvisual. Atas dasar inilah, estetika kemudian tidak hanya mengkaji semata tentang keindahan tetapi juga bagaimana budaya kita saat ini berlangsung.

Sebagai salah satu bentuk ekspresi budaya, estetika sangat penting untuk dapat memahami bagaimana konstruksi budaya berlangsung bahkan pada media terbarukan seperti karakter di dalam gim MOBA Lokapala yang akan kita bahas ini. Gim ini menjadi budaya visual yang sangat menarik untuk dikaji dan oleh karena itu penelitian ini berusaha untuk melihat bagaimana estetika terutama 'kenusantaraan' yang ada di dalam karakter-karakternya.

Gim Lokapala adalah gim MOBA yang diproduksi oleh studio Anantarupa. Saat ini telah diunduh lebih dari 1 juta kali. Nama Lokapala berarti 'Penjaga Jagat', terdiri dari 2 kata yang diambil dari bahasa Sanskerta "Loka" yang berarti jagat dan "Pala" yang artinya penjaga. Ada total 20 karakter yang disebut Ksatriya di dalam gim MOBA Lokapala: Nala, Skar, Haya, Handaru, Kanta, Ilya, Ma'esh, Jinno, Nisha, H'rtal, Saira, Tarja, Sena, 


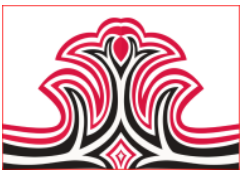

Rajapatni, T'Pala, Vijaya, Sabara, Binara, Neera, dan Nada. Masing-masing dari mereka memilini role masing-masing: 5 dengan role fighter, 4 role mage, 3 role marksman, 3 role assassin, 3 role tank, dan 2 role support.

Ke-20 karakter Ksatriya di atas mengadaptasi tokohtokoh di Nusantara. Sehingga, dapat dikatakan bahwa desain karakter di dalam gim merupakan teks yang dikontruksi yang kemudian menjadi 'mandiri' dari nilai-nilai yang melekat pada karakter sebelumnya. Ketika karakter dalam gim ini menjadi 'mandiri' maka desain karaktrer tersebut secara leluasa dapat menjelaskan backstory dan personality yang kemudian mampu 'mengikat' penggunanya dalam konteks yang terkini-semacam pengikat atau Engagement.

Dalam penelitian ini, kami hanya akan menganalisis 4 karakter saja. yaitu: Jinno, Vijaya, Nala, Ilya. Keempat karakter yang kami pilih ini didasarkan atas adaptasi yang diambil lebih signifikan untuk dianalisis karena mengadaptasi tokoh-tokoh kerajaan Majapahit dan pewayangan. Jinno mengadaptasi dari Gajah Mada.Vijaya mengadaptasi Raden Wijaya, Nala diadaptasi daeri Laksamana kerajaan Majapahit yaitu Mpu Nala dan Ilya mengadaptasi Gatot Kaca.
Gorga : Jurnal Seni Rupa

Volume 10 Nomor 02 Juli-Desember 2021

p-ISSN: 2301-5942 | e-ISSN: 2580-2380

Tabel 1. Analisis Estetika Karakter dalam gim Lokapala (lokapala, 2021)
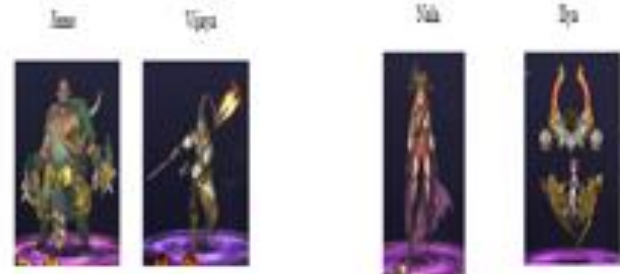

\begin{tabular}{|c|c|c|c|}
\hline 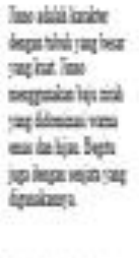 & 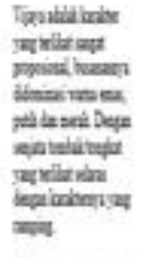 & 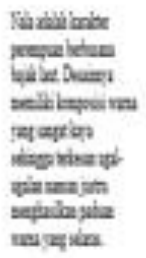 & 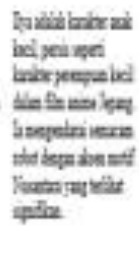 \\
\hline 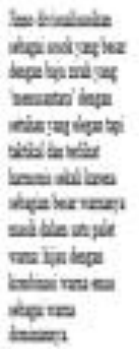 & 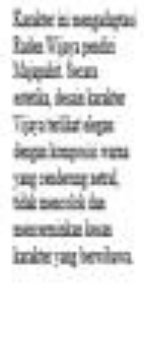 & 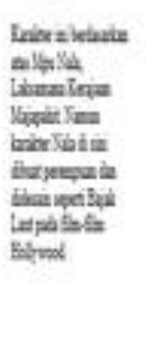 & 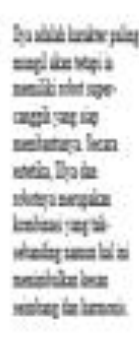 \\
\hline 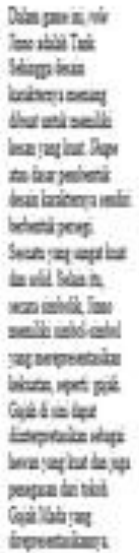 & 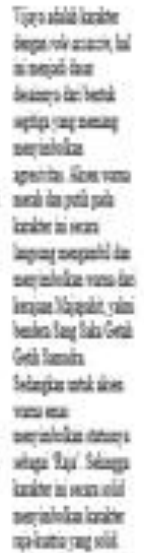 & 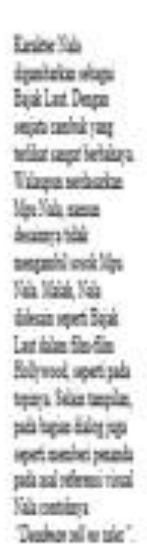 & 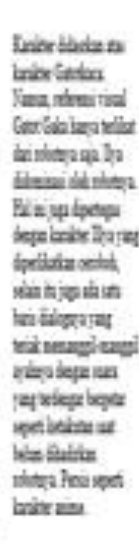 \\
\hline
\end{tabular}

Berikut ini adalah tahap penilaian dari karakterkarakter yang telah dianalisis di atas: karakter Jinno memang tidak dapat dilihat sebagai karakter Gajah Mada secara historis. Namun, karakter ini secara visual cukup memperlihatkan 'kenusantaraannya' melalui penggunaan baju zirahnya yang berdasrkan hasil penelusuran kami mengambil elemen visual dari beberapa relief zaman Majapahit. Meskipun memang dilebih-lebihkan seperti pada armor dan bentuk senjatanya. Busana Vijaya tidak memperlihatkan unsur estetika Nusantara. Busananya malah terlihat seperti pendekar pada film 'persilatan' China. Satu-satunya 'kenusantaraan' yang terlihat adalah batiknya itu pun tidak signifikan. Karakter ini sepertinya tidak didasarkan Vijaya Raja, sangat mungkin Vijaya-muda, seorang ksatria. Tidak ada rujukan desain Raden Wijaya dari artefak tertentu, misalnya arca Harihara. 
Namun ada beberapa referensi visual kerajaan Majapahit, seperti kelat bahu, dan hiasan rambutnyanamun itu pun tidak domin

Selanjutnya, kita melihat karakter Nala yang divisualisasikan sebagai seorang Bajak Laut, sama sekali tidak ada rujukan kepada referensi visual 'kenusantaraan' secara historisnya - terutama bila dikaitkan dengan karakter Laksamana Majapahit Mpu Nala. Karakter ini secara estetika memperlihatkan kewacanaan yang begitu jauh dari Mpu Nala yang menjadi sumber rujukannya. Karakter Ilya secara estetika tidak mencerminkan 'kenusantaraan' sama sekali. Hanya saja ada aksen Gatotkaca dalam robotnya. Seperti pada bagian sayap robot Ilya yang diadaptasi dari bentuk topi atau mahkota dari Gatotkaca (Caping Basunanda). Jika dilihat dari karakter Ilya sendiri sangat tidak realis dan terlihat lebih mengadaptasi karakter perempuan dalam anime Jepang - dengan poporsi wajah yang kecil dengan mata yang besar.

\section{KESIMPULAN DAN SARAN}

\section{Kesimpulan}

Ada beberapa ketidaksesuaian dari gambaran umum tokoh-tokoh yang mendasari desain karakternya. Pada karakter Jinno terdapat beberapa perbedaan seperti badannya yang besar, karena secara historis tidak ada catatan mengenai bentuk badan Gajah Mada yang akurat juga pada bagian senjata-Ia tidak menggunakan keris tapi perisai. Hal ini merupakan penyesuaiannya dengan rolenya sebagai tank untuk menunjukan karakter dengan pertahanan yang sangat kuat. Contoh lainnya adalah karakter Ilya yang digambarkan sebagai anak kecil ceroboh yang sangat jauh berbeda dengan gambaran Gatotkaca yang secara umum yang dikenali di Nusantara, yang biasa digambarkan sebagai sosok pria dengan kekuatan yang luar biasa.

Penambahan dan pengurangan yang terjadi dalam keempat Ksatriya Lokapala dilakukan untuk menyesuaikan rolenya di dalam gim. Hal ini menjadikan keempat karakter tersebut memiliki wacana yang lebih baru daripada karakter yang mereka rujuk. Sehingga dari penelitian ini, kami menemukan bahwa adaptasi keempat karakternya secara historis dan kultural tidak sesuai dan jauh dari akurasi sejarah. Namun sekali lagi hal ini menjadi niscaya dalam prosesnya, dalam industri. Saat ini, estetika tidak hanya mengkaji keindahan tetapi juga bagaimana budaya kita saat ini berlangsung. Sebagai salah satu bentuk ekspresi budaya, estetika sangat penting untuk dapat memahami bagaimana konstruksi budaya berlangsung bahkan
Gorga : Jurnal Seni Rupa

Volume 10 Nomor 02 Juli-Desember 2021 p-ISSN: 2301-5942 | e-ISSN: 2580-2380

pada media terbarukan alangkah lebih baiknya jiga karakter-karakter tersebut diatas lebih memperhatikan aspek sejarahnya sehingga ragam visual yang muncul dalam karakternya dapat menjadi sebagai media pembelajaran bagi generasi saat ini

\section{Saran}

Berdasarkan penelitian yang telah kami lakukan, kami sangat berharap hasil penelitian ini dapat menjadi rujukan dalam penelitian serupa ataupun menjadi bahan berdiskusi bagi para akademisi dan masyarakat yang meminati gim-terutama dalam konteks kebudayaannya. Selain itu, kami berharap penelitian ini memicu diskursus tentang dunia gim di Indonesia karena gim dalam konteks ini menjadi media yang turut mengupayakan pelestarian budaya kita, Nusantara, Indoneisa.

\section{DAFTAR RUJUKAN}

Howard, Lune., dan Bruce L. Berg. (2017). Qualitative Research Methods for the Social Sciences ed ke 9. England: Pearson.

Lokapala. (2021). Game Lokapala. https://lokapala.anantarupa.com/ (diakses tanggal 23 Juni 2021).

Pisani, Elizabeth. (2015). Indonesia Etc.: Exploring the Improbable Nation. London: Granta Publication.

Senoprabowo, A., Khamadi, K., Haryadi, T., \& Yudani, H. D. (2017). Persepsi Visual Karakter Warrior pada Game Online Warcraft, Perfect World, dan Nusantara Online. Demandia: Jurnal Desain Komunikasi Visual, Manajemen Desain, dan Periklanan, 5(-), 160-181.

Smith, Murray. (1995). Engaging Character: Fiction, Emotion, and Cinema. New York: Oxford University Press.

Soewardikoen, W. Didit. (2019). Metodologi Penelitian Desain Komunikasi Visual. Yogyakarta: Penerbit PT Kanisius.

Suryajaya, Martin. (2016). Sejarah Estetika: Era Klasik Sampai Kontemporer. Jakarta dan Yogyakarta: Gang Kabel dan Indie Book Corner.

Triyanto. (2008). Estetika Nusantara: Sebuah Perspektif Budaya. Imajinasi Jurnal Seni, 4(1), 1-14. 